\title{
Intercentre reproducibility of second eigenvector orientation in cardiac diffusion tensor imaging
}

\author{
Elizabeth M Tunnicliffe ${ }^{1 *}$, Pedro Ferreira ${ }^{2}$, Andrew D Scott ${ }^{2}$, Rina Ariga ${ }^{1}$, Laura-Ann McGill ${ }^{2}$, \\ Sonia Nielles-Vallespin ${ }^{2,3}$, Stefan Neubauer ${ }^{1}$, Dudley J Pennell ${ }^{2}$, Matthew D Robson ${ }^{1}$, David Firmin ${ }^{2}$ \\ From 19th Annual SCMR Scientific Sessions \\ Los Angeles, CA, USA. 27-30 January 2016
}

\section{Background}

Diffusion tensor imaging enables the study of cardiac microstructure in vivo, including its changes through the cardiac cycle. The left ventricle consists of myocytes with opposing helical arrangements in the epi- and endocardium. Histology shows that these myocytes are arranged into small laminar "sheetlet" structures, separated by shear layers which allow the sheetlets to move and reorient relative to each other during myocardial contraction. While the direction of the first eigenvector of the cardiac diffusion tensor indicates the average direction of the myocytes in a voxel, the second eigenvector appears to indicate the mean orientation of the sheetlets (1). Recent work has demonstrated that there are differences between the motion of these sheetlets between healthy volunteers and patients with hypertrophic cardiomyopathy (2). In order to facilitate comparison of sheetlet orientations in disease between different centres, the aim of this study was to test the intercentre reproducibility of the second eigenvector orientation.

\section{Methods}

Ten healthy volunteers were scanned at two centres using a stimulated echo cardiac diffusion tensor sequence (3) on different models of 3T MRI scanner. The two centres calculated the second eigenvector angle (E2A) for each volunteer in both systole and diastole in a single mid-ventricular slice using scripts written independently in Matlab (Mathworks, Natick, MA). The mean magnitude of E2A (denoted |E2A|) was calculated over similarly drawn (3) ROIs covering the left ventricle to produce a single number for each subject in systole and diastole. Bland-Altman analysis was carried out on the values for each centre, and statistical significance of differences tested using a paired t-test. The mean intrasubject, intercentre coefficient of variance was calculated.

\section{Results}

Example maps for one of the volunteers are shown in Figure 1. Mean $|\mathrm{E} 2 \mathrm{~A}| \pm$ standard deviation for all subjects averaged over both centres was $55 \pm 4^{\circ}$ in systole and $21 \pm 5^{\circ}$ in diastole. A Bland-Altman plot comparing the $|\mathrm{E} 2 \mathrm{~A}|$ measurements from the two centres is shown in Figure 2. The mean intercentre difference in systole was $0.2 \pm 5^{\circ}(\mathrm{p}=0.9)$ and in diastole was $0.9 \pm 5^{\circ}(\mathrm{p}=$ $0.6)$, giving limits of agreement between $46^{\circ}$ and $65^{\circ}$ in systole and $12^{\circ}$ and $30^{\circ}$ in diastole. The intrasubject coefficient of variation was $7 \%$ for systolic $|\mathrm{E} 2 \mathrm{~A}|$ and $15 \%$ for diastolic $|\mathrm{E} 2 \mathrm{~A}|$. The $\mathrm{CoV}$ is higher in diastole primarily because of the lower numeric value of the sheetlet angle in diastole, not because of higher variance in the measurements.

\section{Conclusions}

In healthy volunteers, it is possible to obtain consistent evaluations of the second eigenvector angle, a measure of the myocardial sheetlet orientation, at two different centres running equivalent stimulated echo cardiac diffusion tensor sequences.

\footnotetext{
Authors' details

${ }^{1}$ OCMR, University of Oxford, Oxford, UK. ${ }^{2} \mathrm{NIHR}$ Cardiovascular BRU, Royal Brompton Hospital \& Imperial College, London, UK. ${ }^{3}$ National Institutes of Health, National Heart Lung and Blood Institute, Bethesda, MD, USA.
}

Published: 27 January 2016

${ }^{1}$ OCMR, University of Oxford, Oxford, UK

Full list of author information is available at the end of the article 

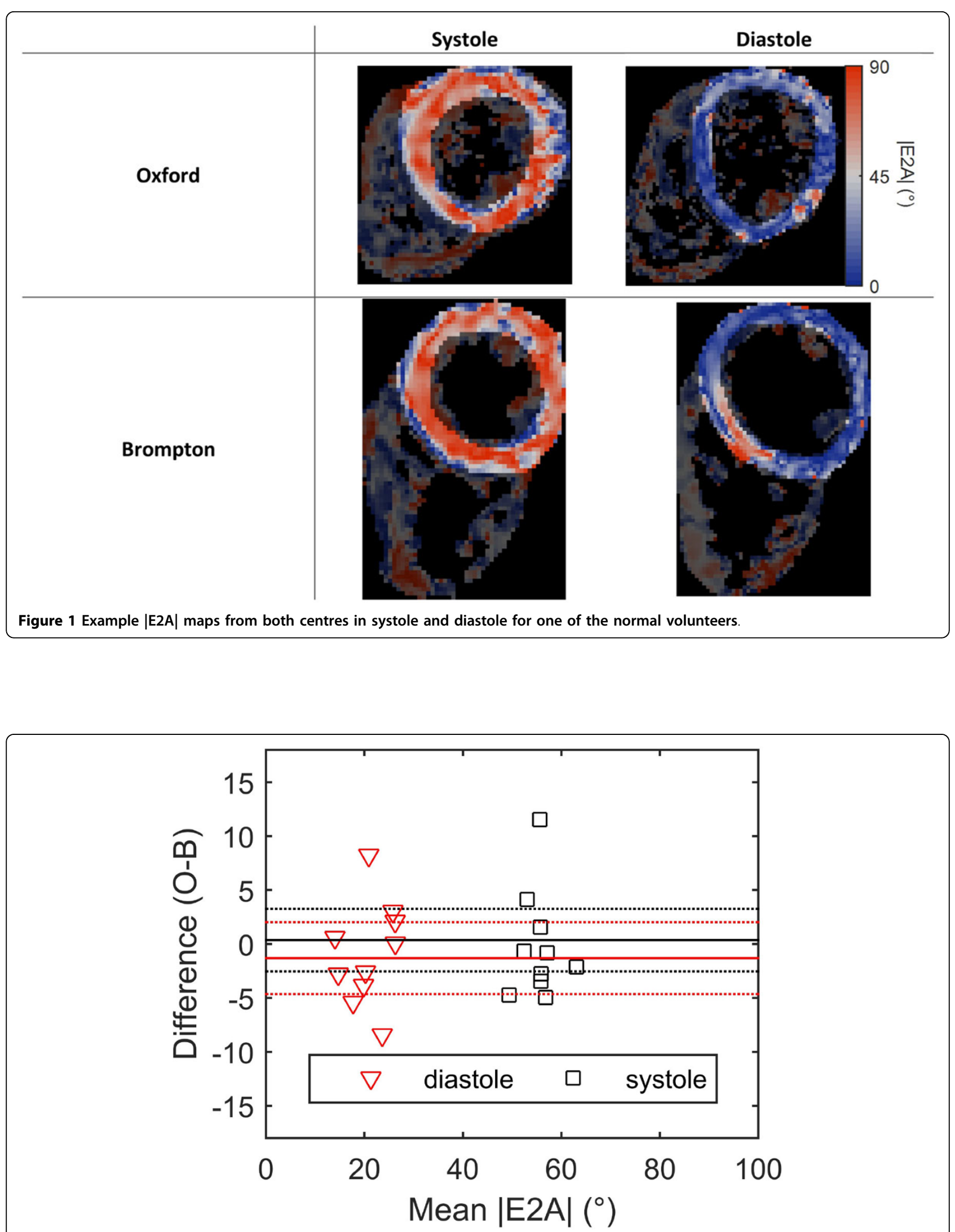

Figure 2 A Bland-Altman plot showing the differences between the $|\mathrm{E} 2 \mathrm{~A}|$ measured at the two centres 


\section{References}

1. Hales, et al: Prog Biophys Mol Biol 2012, 110:P36-30.

2. Ferreira, et al: J Cardiovasc Magn Reson 2014, 16:87.

3. Tunnicliffe, Scott, et al: J Cardiovasc Magn Reson 2014, 16:31.

doi:10.1186/1532-429X-18-S1-P35

Cite this article as: Tunnicliffe et al:: Intercentre reproducibility of second eigenvector orientation in cardiac diffusion tensor imaging. Journal of Cardiovascular Magnetic Resonance 2016 18(Suppl 1):P35.

Submit your next manuscript to BioMed Central and take full advantage of:

- Convenient online submission

- Thorough peer review

- No space constraints or color figure charges

- Immediate publication on acceptance

- Inclusion in PubMed, CAS, Scopus and Google Scholar

- Research which is freely available for redistribution

Submit your manuscript at www.biomedcentral.com/submit
() Biomed Central 